\title{
Large left ventricular aneurysm
}

Antonio Grimaldi, MD, Alessandro Castiglioni, MD, Michele De Bonis, MD, and Ottavio Alfieri, FECTS

Video clip is available online.

This article reports the surgical treatment of a 70-year-old man with a clinically relevant large left ventricular aneurysm caused by chronic occlusion of the right coronary artery. Transthoracic and transesophageal echocardiography showed a large aneurysm spreading over the inferolateral wall and complicated by thrombotic stratification (Figure 1). A severe functional mitral regurgitation secondary to posteromedial papillary muscle displacement was

From the Cardiovascular and Thoracic Department, San Raffaele Scientific Institute and Università Vita-Salute San Raffaele, Milan, Italy.

Disclosures: Authors have nothing to disclose with regard to commercial support. Received for publication May 17, 2011; accepted for publication May 20, 2011. Address for reprints: Antonio Grimaldi, MD, Cardiovascular and Thoracic Department, San Raffaele Scientific Institute, via Olgettina 60, 20132 Milan, Italy (E-mail: grimaldi.antonio@hsr.it).

J Thorac Cardiovasc Surg 2011;142:940-1

$0022-5223 / \$ 36.00$

Copyright (C) 2011 by The American Association for Thoracic Surgery doi:10.1016/j.jtcvs.2011.05.008 also noted (Video 1). The patient underwent surgical resection of the left ventricular aneurysm (Dor procedure) using a bovine endoventricular patch and mitral valve replacement (Figure 2).$^{1-7}$

\section{References}

1. Dor V, Kreitmann P, Jourdan J. Interest of physiological closure (circumferential plasty on contractile areas) of left ventricle after resection and endocardectomy for aneurysm or akinetic zone: comparison with classical technique about a series of 209 left ventricular resections. J Cardiovasc Surg. 1985;26:73.

2. Buckberg G. Left ventricular reconstruction for dilated ischaemic cardiomyopathy: biology, registry, randomisation and credibility. Eur J Thorac Cardiovasc Surg. 2006;30:753-61.

3. Dor V, Civaia F, Alexandrescu C, Sabatier M, Montiglio F. Favorable effects of left ventricular reconstruction in patients excluded from the Surgical Treatments for Ischemic Heart Failure (STICH) trial. J Thorac Cardiovasc Surg. 2011;141.905-16.e4.

4. Khanna D, Vengala S, Miller AP, et al. Quantification of mitral regurgitation by live three-dimensional transthoracic echocardiographic measurements of vena contracta area. Echocardiography. 2004;21:737-43.

5. Cohn JN, Ferrari R, Sharpe N. Cardiac remodeling-concepts and clinical implications: a consensus paper from an international forum on cardiac remodeling: on behalf of an International Forum on Cardiac Remodeling. J Am Coll Cardiol. 2000;35:569-82.

6. Konen E, Merchant N, Gutierrez C, et al. True versus false left ventricular aneurysm: differentiation with MR imaging - initial experience. Radiology. 2005;236: 65-70.

7. Adhyapak SM, Parachuri VR. Architecture of the left ventricle: insights for optimal surgical ventricular restoration. Heart Fail Rev. 2010;15:73-83. Review.
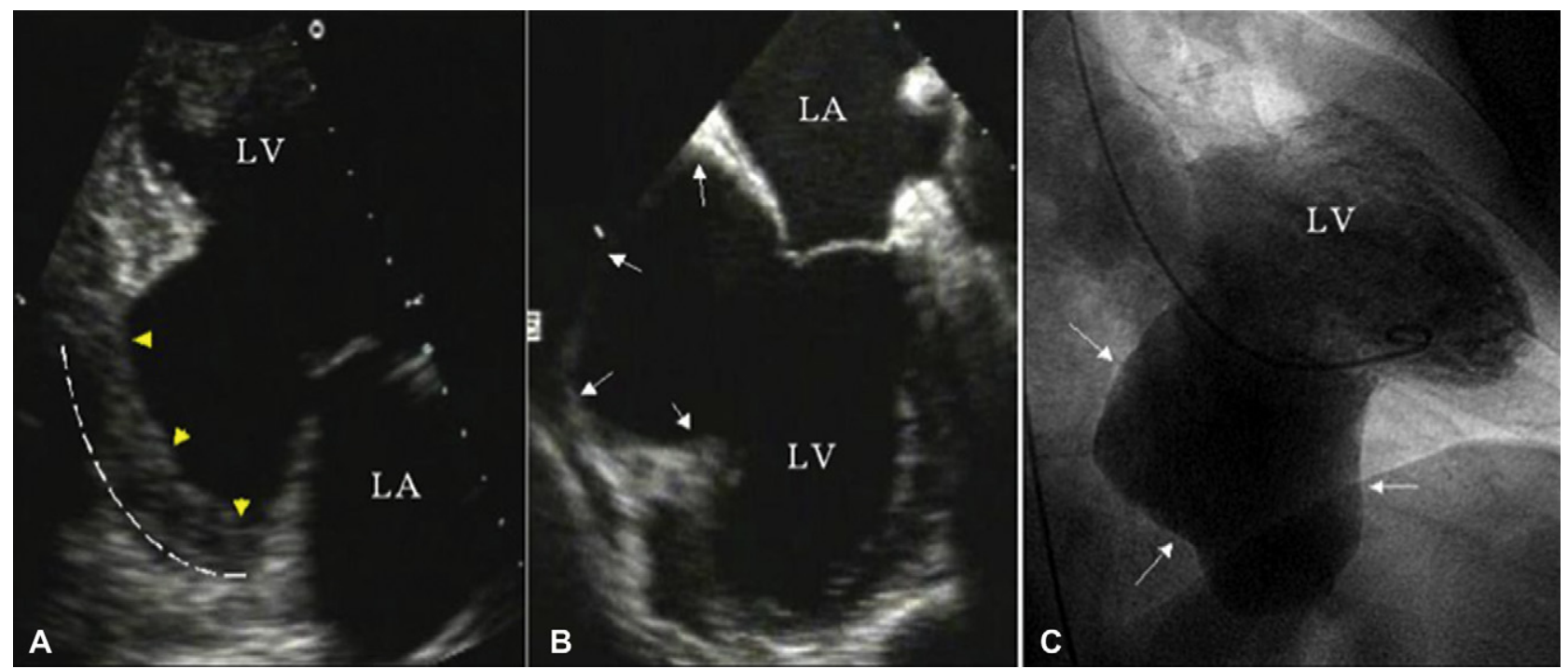

FIGURE 1. Transthoracic echocardiography shows the inferolateral aneurysm (A, white dotted line) occupied by thrombotic stratification (yellow arrows) and confirmed by transesophageal study $(\mathrm{B}$, white arrows). Preoperative left ventricular angiography shows the extent of the aneurysmatic sac $(\mathrm{C}$, white arrows) and its independence from the cardiac cycle. $L A$, Left atrium; $L V$, left ventricle. 

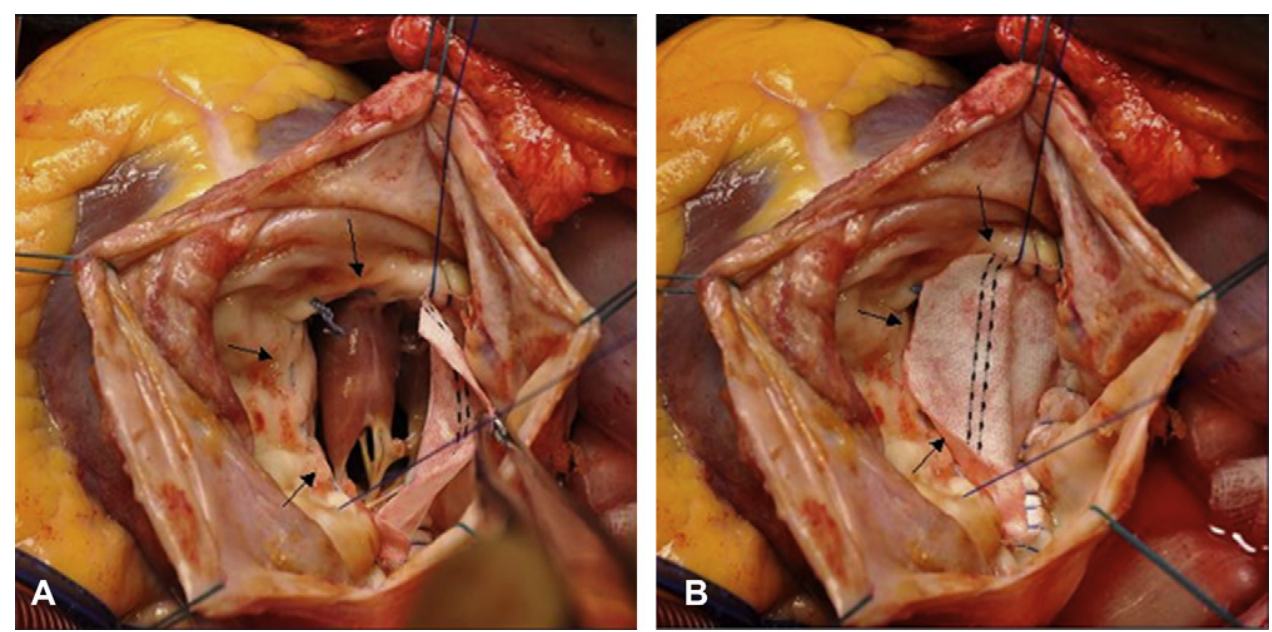

FIGURE 2. A, The aneurysm is entered, and the intracavitary thrombus is extracted. Visual inspection of the papillary muscle and the edge between the aneurysmal scar tissue and the viable contracting myocardial (black arrows). B, The endocardial patch (black arrows) is secured in place with interrupted vertical mattress sutures placed through the edges of the patch. 